\title{
A cluster of invasive meningococcal disease in young men who have sex with men in Berlin, October 2012 to May 2013
}

U Marcus (marcusu@rki.de) ${ }^{1}$, U Vogel ${ }^{2}$, A Schubert ${ }^{3}$, H Claus $^{2}$, J Baetzing-Feigenbaum ${ }^{3}$, W Hellenbrand ${ }^{1}, 0$ Wichmann ${ }^{1}$

1. Department for Infectious Disease Epidemiology, Robert Koch Institute, Berlin, Germany

2. University of Würzburg, Institute for Hygiene and Microbiology and National Reference Laboratory for Meningococci, Würzburg, Germany

3. Infectious Disease Protection and Epidemiology Unit, State Office for Health and Social Affairs (LAGeSo), Federal State of Berlin, Berlin, Germany

Marcus U, Vogel U, Schubert A, Claus H, Baetzing-Feigenbaum J, Hellenbrand W, Wichmann 0 . A cluster of invasive meningococcal disease in young men who have sex with men in Berlin, October 2012 to May 2013. Euro Surveill. 2013;18(28):pii=20523. Available online: http://www.eurosurveillance.org/ViewArticle. aspx?Articleld $=20523$

Article submitted on 08 July 2013 / published on 11 July 2013

Between October 2012 and May 2013, five cases of invasive meningococcal disease in young men who have sex with men (MSM) living in Berlin were notified to local health authorities in Germany. Three of the five cases died. All were caused by serogroup $C$ variants with the finetype $\mathrm{P}_{1} \cdot 5-1,10-8: F_{3}-6$. Awareness was increased through the use of community networks; an extension of the existing vaccination recommendation to all MSM is currently being considered.

As of 2 July 2013, 208 cases of invasive meningococcal disease (IMD) were reported in Germany since the beginning of the year, which is similar to previous years (2012: 189 cases; 2011: 224 cases). Among the cases reported from Berlin $(n=17)$ were three cases of IMD due to MenC in young men who have sex with men (MSM).

IMD is a rare but serious disease caused by Neisseria meningitidis, a gram-negative, encapsulated diplococcus. The clinical spectrum of IMD is diverse and may vary from a mild febrile illness to septicaemia and/or meningitis, which may progress to fulminant disease, multi-organ failure and death within hours [1]. The proportion of patients who develop severe disease increases with age [2].

Twelve distinguishable serogroups have been described [3]. N. meningitidis serogroups B (MenB) and $C$ (MenC) predominate in Germany and affect mainly young children and adolescents [4]. Annual IMD incidence in Germany was 0.45 per 100,000 in the years 2010 to $2012(n=386, n=369, n=354)$ [5]. Among young adults aged 20-29 years, IMD incidence in 2010 to 2012 was 0.65 per 100,000 . Case fatality in 2012 was $9.3 \%$ and was highest in patients with MenC (13\%) [5].

In 2006, the German Standing Committee on Vaccination (STIKO) recommended routine MenC vaccination in the second year of life. Catch-up vaccination for all children and adolescents under the age of 18 years on an individual basis is recommended, but a catch-up campaign was not undertaken. In 2010, MenC vaccination coverage at school entry ranged between $53 \%$ and $90 \%$ in the 16 German federal states [4]. In addition to routine childhood vaccination, STIKO recommends vaccination against serogroups $A, C, W_{135}$ and $Y$ for high-risk individuals independent of their age (i.e. patients with asplenia or immunocompromised individuals including those infected with human immunodeficiency virus (HIV)). However, meningococcal vaccine coverage among HIV patients in Germany is unknown. Vaccines are free of charge in Germany if officially recommended, but can otherwise be individually purchased if prescribed by a physician.

\section{Description of cases}

Case 1 was a man in his early 20s. He developed chills, fever and severe abdominal pain in early February, was hospitalised, and died during abdominal surgery within 10 hours after hospital admission. MenC was found in blood culture. The patient had visited several gay venues in Berlin in the days before falling ill. Cases 2 and 3 were both in their mid-20s. They visited a gay nightclub in May and spent the following night together. Two days later, Case 2 developed symptoms (fever, nausea, vomiting, irritability, stiff neck), was hospitalised, and treated in an intensive care unit. He survived, but suffers from irreversible brain damage. Case 3 developed symptoms a day later (irritability, fever, nausea), but did not seek medical care and died at home on the following day. An autopsy revealed death due to septic shock and disseminated intravascular coagulation. MenC was detected in cerebrospinal fluid.

Besides smoking (two cases) and attending gay bars, no other risk factors were reported. None of the three young men had been diagnosed with HIV, and none of 
the three was vaccinated against MenC. While a common source or direct transmission between Cases 2 and 3 seems likely, no direct link between Case 1 and Cases 2 and 3 was found. No links to men who visited or lived in cities with concurrent or recent IMD outbreaks among MSM (e.g. Paris or New York) could be established $[6,7]$.

\section{Molecular typing}

All three infections were due to $N$. meningitidis serogroup C: PorA-VR1 5-1, PorA-VR2 10-8: FetA F3-6 (C:P1.51,10-8:F3-6) and confirmed as sequence type (ST) 11. Analysis of position 640 of the fum $C$ gene revealed that the strains belonged to a subclone of ST-11 designated electrophoretic type (ET) 15, which has caused a number of small outbreaks in Germany since 1998 [8]. The PorA and FetA variants are classically linked to ET-15

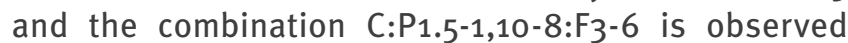
frequently. Therefore, three further typing loci were included, i.e. por $\mathrm{B}, \mathrm{Hbp}$, and penA. All three isolates were identical also with regard to these markers: por $B$ allele 2-2, fHbp allele 766, and penA allele 3 . This finding supports the hypothesis of a local cluster and link between the three cases.

\section{Retrospective epidemiology}

In an analysis of data from the German disease notification system restricted to IMD cases aged 15 to 49 years occurring in the five largest metropolitan areas (i.e. Berlin, Hamburg, Munich, Cologne and Frankfurt), we identified in total $n=15, n=11, n=14$ and $n=20$ reported IMD cases in calendar weeks 1 to 27 for 2010, 2011, 2012 and 2013, respectively. In these five areas, the proportion of males with IMD in this specific agegroup ranged between $40 \%$ and $54 \%$ in the period 2010 to 2012 , whereas this proportion was $80 \%$ in 2013 . In contrast, the sex distribution remained similar over the years when the analysis was not restricted to the five metropolitan areas (57\%, 58\%, 62\% and $61 \%$ males, respectively).

When the local health authorities in Berlin became aware of this potential IMD outbreak among MSM, they investigated retrospectively if any of the other invasive MenC cases in young men notified in 2012-13 were MSM. Two additional cases were identified. One case was notified in February 2013, the other case in October 2012, both were in their late 20s. The latter case had developed signs of sepsis and died. Isolates from both cases had been characterised at the German Reference Laboratory for Meningococci as the same finetype PorA-VR1:5-1; PorA-VR2:10-8 and FetA:3-6. As the isolates were still available, further genetic typing was possible. Complementary typing has to date only been conducted for one isolate. The strain obtained from the case notified in February 2013 differed from the variant found in the series of Cases 1-3 with regard to the penA allele (penA-2) and the fhbp allele (new variant). This finding suggests that at least this case was caused by a highly related, yet distinct variant and that more than one strain was involved in this cluster of five cases.

\section{Public health response}

From October 2012 until the end of June 2013, the incidence of MenC IMD among the MSM community in Berlin was $6.3 / 100,000$ based on five reported cases and an estimated number of 80,000 MSM in the community [9]. This is below the threshold of an epidemic situation (defined in Germany as $\geq 10$ cases/100,000 in a given region within three months), but almost 10 -fold higher than expected for young male adults in this age group for the entire year $(0.65 / 100,000$ with inclusion of all serogroups).

Infectious disease surveillance networks in Germany and healthcare professionals in Berlin were alerted to the detection of this IMD cluster among MSM, which will help to identify additional cases rapidly if they occur. The German AIDS support organisation Deutsche AIDS Hilfe has issued information on the cluster on their website as a first measure to inform the MSM community about symptoms of the disease and the existing recommendation to vaccinate HIVpositive individuals against IMD. According to STIKO, the existing meningococcal vaccination recommendation targeting risk groups (such as HIV patients) can be extended to other population subgroups by the responsible health authorities during regional outbreaks, taking into account the epidemiological and temporal associations between notified cases [10]. Since no HIV patients have been identified in the MSM cluster as of today, the state health authority in Berlin is currently considering the option of extending the existing vaccination recommendation to all MSM to prevent further cases.

\section{Acknowledgements}

We thank the local public health offices for collecting the relevant information and local laboratories for sending samples to the National Reference Center for Meningococci to conduct further molecular typing of strains.

\section{Conflict of interest}

None declared.

\section{Authors' contributions}

U. Marcus drafted the manuscript and participated in the outbreak investigation. U. Vogel supervised molecular typing of the bacterial isolates and contributed to the manuscript. A. Schubert provided data on the initial three-case cluster and initiated the retrospective case finding. $\mathrm{H}$. Claus did the molecular typing of the isolates and contributed to the manuscript. J. Baetzing-Feigenbaum provided data on the cluster of five MSM from Berlin. W. Hellenbrand contributed to the manuscript. 0 . Wichmann coordinated the outbreak investigation and contributed to the manuscript. 


\section{References}

1. Pace D, Pollard AJ. Meningococcal disease: clinical presentation and sequelae. Vaccine. 2012;30 Suppl 2:B3-9. http://dx.doi.org/10.1016/j.vaccine.2011.12.062. PMid:22607896.

2. Cohn AC, MacNeil JR, Harrison LH, Hatcher C, Theodore J, Schmidt M, et al. Changes in Neisseria meningitidis disease epidemiology in the United States, 1998-2007: implications for prevention of meningococcal disease. Clin Infect Dis. 2010;50(2):184-91. http://dx.doi.org/10.1086/649209. PMid:20001736.

3. Harrison OB, Claus H, Jiang Y, Bennett JS, Bratcher HB, Jolley KA, et al. Description and nomenclature of Neisseria meningitidis capsule locus. Emerg Infect Dis. 2013;19(4):56673. http://dx.doi.org/10.3201/eid1904.111799. PMid:23628376. PMCid:PMC3647402.

4. Hellenbrand W, Elias J, Wichmann O, Dehnert M, Frosch M, Vogel U. Epidemiology of invasive meningococcal disease in Germany, 2002-2010, and impact of vaccination with meningococcal C conjugate vaccine. J Infect. 2013;66(1):48-56. http://dx.doi.org/10.1016/j.jinf.2012.09.008. PMid:23043893.

5. Robert Koch-Institut (RKI). Infektionsepidemiologisches Jahrbuch meldepflichtiger Krankheiten für 2012. [Annual epidemiological report on notifiable diseases for 2012] Berlin: RKI; 2013. German. Available from: http://www.rki.de/DE/ Content/Infekt/Jahrbuch/jahrbuch_node.html

6. Simon MS, Weiss D, Gulick RM. Invasive Meningococcal Disease in Men Who Have Sex With Men. Ann Intern Med. 2013 Jun 17 http://dx.doi.org/10.7326/0003-4819-159-4-201308200-00674. PMid:23778867.

7. European Center for Disease Prevention and Control (ECDC). Rapid Risk Assessment: Invasive meningococcal disease among men who have sex with men. Stockholm: ECDC; 2013. Available from: http://www.ecdc.europa.eu/en/publications/ Publications/rapid-risk-assessment-invasive-meningococcaldisease-among-MSM.pdf

8. Elias J, Vogel U. IS1301 fingerprint analysis of Neisseria meningitidis strains belonging to the ET-15 clone. J Clin Microbiol. 2007;45(1):159-67. http://dx.doi.org/10.1128/ JCM.01322-06. PMid:17093016. PMCid:PMC1828961.

9. Marcus U, Schmidt AJ, Hamouda O, Bochow M: Estimating the regional distribution of men who have sex with men (MSM) based on Internet surveys. BMC Public Health. 2009;9:180. http://dx.doi.org/10.1186/1471-2458-9-180. PMid:19519888. PMCid:PMC2702383.

10. German Standing Committee on Vaccination. Empfehlungen der Ständigen Impfkommission (STIKO) am Robert KochInstitut. [Recommendations of the Standing Committee on Vaccination (STIKO) at the Robert Koch Institute]. Epidemiol Bull. 2012;30:283-310. German. Available from: http://www. rki.de/EN/Content/Prevention/Vaccination/recommandations/ STIKO_Recommendations_2012_en.pdf?_blob=publicationFile 